\title{
Progress Towards the Total Synthesis of Trichodermamide A and B: the Construction of the Oxazine Moiety
}

\author{
Xiaobo Wan, Gabriel Doridot, Madeleine M. Joullié*
}

Supporting Information

1

Methyl (-)-3, 4-O- isopropylidene-5-O-(tert-butyldiphenylsilyl)quinate

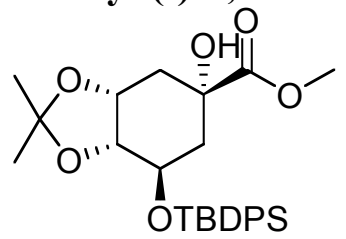

A mixture of Methyl (-)-3,4-O- Isopropylidenequinate (11.27 g, $45.8 \mathrm{mmol})$ and imidazole (9.36 g, $137.4 \mathrm{mmol}$ ) was dissolved in $100 \mathrm{ml}$ dry $\mathrm{CH}_{2} \mathrm{Cl}_{2}$ and cooled down to $0^{\circ} \mathrm{C}$. To this solution, was added dropwise $14.28 \mathrm{ml}$ tert-butyldiphenylchlorosilane. The reaction mixture was allowed to gradually warm up to rt and stirred over night. The reaction was then quenched with saturated $\mathrm{NH}_{4} \mathrm{Cl}$ aqeous solution and the organic layer was separated, washed with brine, dried with $\mathrm{Na}_{2} \mathrm{SO}_{4}$ and then concentrated under vacuum. The crude product was purified by column chromatography ( $50 \%$ EtOAc/50\% Hexanes, $\left.R_{\mathrm{f}} 0.77\right)$ to give a colorless oil $3(22.20 \mathrm{~g}, 100 \%)$. ${ }^{1} \mathrm{H}$ NMR $\left(\mathrm{CDCl}_{3}\right): \delta$ 7.76-7.73 $(4 \mathrm{H}, \mathrm{m}), 7.67-7.64(6 \mathrm{H}, \mathrm{m}), 4.48-4.44(1 \mathrm{H}, \mathrm{m}), 4.20-4.15(1 \mathrm{H}$, m), 4.10-4.07 (1 H, m), $3.72(3 \mathrm{H}, \mathrm{s}), 3.18(1 \mathrm{H}, \mathrm{b}), 2.31(1 \mathrm{H}, \mathrm{dd}, J=4.6,15.4 \mathrm{~Hz}), 2.14(1 \mathrm{H}$, dd, $J=2.0,15.4 \mathrm{~Hz}), 1.95-1.84(2 \mathrm{H}, \mathrm{m}), 1.28(3 \mathrm{H}, \mathrm{s}), 1.18(3 \mathrm{H}, \mathrm{s}), 1.10(9 \mathrm{H}, \mathrm{s}) ;{ }^{13} \mathrm{C}$ NMR $\left(\mathrm{CDCl}_{3}\right): \delta 174.7,136.0,135.7,134.0,133.3,129.5,127.4,108.6,79.6,73.8,73.5,69.8,52.6$, 39.9, 34.1, 27.4, 26.8, 25.6, 19.1; HRMS (ESI): Calculated for $\mathrm{C}_{27} \mathrm{H}_{36} \mathrm{O}_{6} \mathrm{Si}: 484.2281$, Found (M $\left.+\mathrm{Na}^{+}\right): 507.2178$; IR $\left(\mathrm{cm}^{-1}\right): 3502(\mathrm{~b}), 3071(\mathrm{~m}), 3048(\mathrm{~m}), 2983(\mathrm{~m}), 2955(\mathrm{~s}), 2932(\mathrm{~s}), 2892$ (m), $2857(\mathrm{~s}), 1736(\mathrm{~s}), 1589(\mathrm{w}), 1472(\mathrm{~m}), 1428(\mathrm{~s}), 1381(\mathrm{~m}), 1368(\mathrm{~m}), 1240(\mathrm{~s}), 1218(\mathrm{~s})$, $1163(\mathrm{~m}), 1112$ (s), 1056 (s), 1011 (m), 966 (w), 940 (w), 922 (m), 862 (w), 831 (m), 802 (m); $[\alpha]_{D}{ }^{20}=-52.0^{\circ}$ :

\section{2}

5-(tert-Butyl-diphenyl-silanyloxy)-6, 7-O-isopropylidene-1-Oxa-spiro[2.5]octane

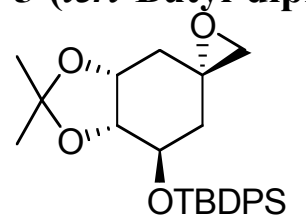

To a solution containing the corresponding mesylate $(9.50 \mathrm{~g}, 17.8 \mathrm{mmol})$ in $200 \mathrm{ml}$ dry THF which was cooled down to $0^{\circ} \mathrm{C}$, was added dropwise LiHMDS (21.3 ml, $1 \mathrm{M}$ solution in THF). The solution was allowed to warm up to rt and stirred for $0.5 \mathrm{~h}$. The reaction was quenched with saturated with saturated $\mathrm{NH}_{4} \mathrm{Cl}$ aqueous solution and the organic layer was separated. The aqueous layer was extracted with EtOAc twice and the organic layers were combined, washed 
with brine, dried with $\mathrm{Na}_{2} \mathrm{SO}_{4}$ and concentrated under vacuum. The crude product was purified by column chromatography $\left(30 \%\right.$ EtOAc/70\% Hexanes, $\left.R_{\mathrm{f}} 0.53\right)$ to give white crystals $6(6.62 \mathrm{~g}$, 85\%). ${ }^{1} \mathrm{H}$ NMR (CDCl3): $\delta$ 7.68-7.61 $(4 \mathrm{H}, \mathrm{m}), 7.47-7.33(6 \mathrm{H}, \mathrm{m}), 4.52(1 \mathrm{H}, \mathrm{dt}, J=4.2,6.2$ $\mathrm{Hz}), 4.18-4.08(2 \mathrm{H}, \mathrm{m}), 2.61(1 \mathrm{H}, \mathrm{d}, J=4.8 \mathrm{~Hz}), 2.48(1 \mathrm{H}, \mathrm{d}, J=4.8 \mathrm{~Hz}), 2.39(1 \mathrm{H}, \mathrm{dd}, \mathrm{J}=$ 4.2, $15.0 \mathrm{~Hz}), 1.94(1 \mathrm{H}, \mathrm{dd}, \mathrm{J}=2.8,14.2 \mathrm{~Hz}), 1.79(1 \mathrm{H}, \mathrm{dd}, \mathrm{J}=4.2,14.0 \mathrm{~Hz}), 1.53-1.46(1 \mathrm{H}$, m), $1.40(3 \mathrm{H}, \mathrm{s}), 1.29(3 \mathrm{H}, \mathrm{s}), 1.08(9 \mathrm{H}, \mathrm{s}) ;{ }^{13} \mathrm{C} \mathrm{NMR}\left(\mathrm{CDCl}_{3}\right): \delta 135.7,135.6,133.7,122.3$, $129.9,127.7,108.6,76.5,72.7,70.0,53.8,53.3,33.8,33.1,27.2,26.9,24.8,19.3$; $\quad$ HRMS (ESI) calculated for $\mathrm{C}_{26} \mathrm{H}_{34} \mathrm{O}_{4} \mathrm{Si}: 438.2226$, Found: $\mathrm{IR}\left(\mathrm{cm}^{-1}\right): \quad[\alpha]_{D}{ }^{20}=0.10^{\circ}\left(\mathrm{c}=2.02, \mathrm{CHCl}_{3}\right)$; mp: $94-96^{\circ} \mathrm{C}$

3

3-[7-(tert-Butyl-diphenyl-silanyloxy)-5-hydroxy-2,2-dimethyl-hexahydro-benzo[1,3]dioxol5-yl]-propionitrile<smiles>CC1(C)O[C@H]2C[C@](O)(CCC#N)C[C@H](O[SbH3])[C@H]2O1</smiles>

The reaction was carried out in Ar atmosphere. To a solution containing $n$-BuLi (16.5 ml, 33.0 mmol, $2 \mathrm{M}$ in cyclohexane) in $100 \mathrm{ml}$ dry THF, was added dropwise diisopropylamine (4.66 ml, $33.0 \mathrm{mmol})$ at $-78^{\circ} \mathrm{C}$ to make a fresh LDA/THF solution. Dry MeCN (1.6 ml, $\left.30.0 \mathrm{mmol}\right)$ was then added dropwise into the fresh LDA/THF solution and the solution was stirred for $1 \mathrm{~h}$ at $78^{\circ} \mathrm{C}$ until white slurry appeared. A THF solution containing the epoxide $2(6.57 \mathrm{~g}, 15.0 \mathrm{mmol}$, in $20 \mathrm{ml}$ THF) was canulated into the slurry and the reaction mixture was allowed to warm up gradually from $-78^{\circ} \mathrm{C}$ to $\mathrm{rt}$. The reaction was then quenched with saturated $\mathrm{NH}_{4} \mathrm{Cl}$ aqueous solution and the organic layer was separated. The aqueous layer was extracted with EtOAc twice and the organic layers were combined, washed with brine, dried with $\mathrm{Na}_{2} \mathrm{SO}_{4}$ and concentrated under vacuum. The crude product was purified by column chromatography $(30 \% \mathrm{EtOAc} / 70 \%$ Hexanes, $\left.R_{\mathrm{f}} 0.48\right)$ to give a colorless oil $7(6.69 \mathrm{~g}, 93 \%) .{ }^{1} \mathrm{H}$ NMR $(\mathrm{CDCl} 3): \delta$ 7.72-7.61 $(4 \mathrm{H}$, m), 7.47-7.32 (6 H, m), $4.48(1 \mathrm{H}$, penta, $J=3.0 \mathrm{~Hz}), 4.11-4.00(2 \mathrm{H}, \mathrm{m}), 2.39-2.31(1 \mathrm{H}, \mathrm{m})$, 2.22-2.15 (1 H, m), 2.12-2.06 (1 H, m), 1.89 (1 H, dd, $J=6.8,3.2 \mathrm{~Hz}), 1.82-1.74(1 \mathrm{H}, \mathrm{m}), 1.70-$ $1.63(2 \mathrm{H}, \mathrm{m}), 1.43-1.37(1 \mathrm{H}, \mathrm{m}), 1.29(3 \mathrm{H}, \mathrm{s}), 1.23(3 \mathrm{H}, \mathrm{s}), 1.08(9 \mathrm{H}, \mathrm{s}) ;{ }^{13} \mathrm{C} \mathrm{NMR}\left(\mathrm{CDCl}_{3}\right): \delta$ 136.0, 135.8, 134.0, 133.2, 129.9, 129.8, 127.7, 127.6, 127.5, 120.4, 108.7, 78.9, 73.9, 70.2, 69.9, 40.6. 38.4, 35.4, 27.4, 27.0, 25.9, 19.8, 10.8; HRMS (ESI) calculated for $\mathrm{C}_{28} \mathrm{H}_{37} \mathrm{NO}_{4} \mathrm{Si}$ : Found $\left(\mathrm{M}+\mathrm{Na}^{+}\right): 502.2389 \mathrm{IR}\left(\mathrm{cm}^{-1}\right): 3500(\mathrm{~b}), 3070(\mathrm{~m}), 3044(\mathrm{~m}), 2931(\mathrm{~s}), 2857(\mathrm{~m}), 2247(\mathrm{w})$, $1472(\mathrm{~m}), 1427$ (s), $1382(\mathrm{~m}), 1241(\mathrm{~m}), 1218(\mathrm{~m}), 1112(\mathrm{~s}), 1045$ (s), 1007 (w), $920(\mathrm{~m}), 827$ $(\mathrm{m}), 740(\mathrm{~m}), 703(\mathrm{~s}) ;[\alpha]_{D}{ }^{20}=-124.5^{\circ}\left(\mathrm{c}=1.43, \mathrm{CHCl}_{3}\right)$

\section{4}

7-(tert-Butyl-diphenyl-silanyloxy)-8,9-O-isopropylidene-1-oxa-spiro[4.5]decanone<smiles>CC1(C)O[C@H]2C[C@@]3(CCC(=O)O3)C[C@@H](O)[C@@H]2O1</smiles>

The nitrile 3 (14.78 $\mathrm{g}$, $30.8 \mathrm{mmol}$ ) was dissolved in $200 \mathrm{ml}$ dry $\mathrm{MeOH}$ and the solution was cooled down to $0^{\circ} \mathrm{C}$. To this solution, was added all at once NaOMe $(5.0 \mathrm{~g}, 92.4 \mathrm{mmol})$. The solution was allowed to warm up to rt, stirred for $3 \mathrm{~h}$ and neutralized with $\mathrm{AcOH}$ (5.29 ml, 92.4 mmol). The solution was then diluted with EtOAc and water, and the mixture was stirred for $4 \mathrm{~h}$ and monitored by TLC until the reaction completed. The organic layer was separated. The 
aqueous layer was extracted with EtOAc twice and the organic layers were combined, washed with brine, dried with $\mathrm{Na}_{2} \mathrm{SO}_{4}$ and concentrated under vacuum. The crude product was purified by column chromatography $\left(50 \% \mathrm{EtOAc} / 50 \%\right.$ hexanes, $\left.R_{\mathrm{f}} 0.55\right)$ to give a colorless oil 8 (10.60 $\mathrm{g}, 97 \%$ based the recovery of $3.90 \mathrm{~g}$ starting material). ${ }^{1} \mathrm{H}$ NMR $(\mathrm{CDCl} 3): \delta 7.72-7.62(4 \mathrm{H}, \mathrm{m})$, 7.47-7.35 (6 H, m), $4.36(1 \mathrm{H}, \mathrm{dd}, J=5.8,10.4 \mathrm{~Hz}), 4.22-4.15(1 \mathrm{H}, \mathrm{m}), 3.98(1 \mathrm{H}, \mathrm{t}, J=10.4$ $\mathrm{Hz}), 2.44-2.35$ (1 H, m), 2.31-2.20 (1 H, m), 2.19-2.13 (1 H, m), 2.13-2.06 (1 H, m), 2.05-1.94 (2 $\mathrm{H}, \mathrm{m}), 1.78(1 \mathrm{H}, \mathrm{dd}, J=2.9,7.0 \mathrm{~Hz}), 1.54(1 \mathrm{H}, \mathrm{dd}, J=3.7,7.0 \mathrm{~Hz}), 1.36(3 \mathrm{H}, \mathrm{s}), 1.25(3 \mathrm{H}$, s), $1.09(9 \mathrm{H}, \mathrm{s}) ;{ }^{13} \mathrm{C} \mathrm{NMR}\left(\mathrm{CDCl}_{3}\right): \delta 176.0,135.9,135.7,133.8,133.1,130.0,127.9,127.7$, $108.8,84.1,77.8,72.2,69.6,38.1,37.2,34.7,28.0,27.7,27.0,25.4,19.0$ HRMS (ESI) calculated for $\mathrm{C}_{28} \mathrm{H}_{36} \mathrm{O}_{5} \mathrm{Si}$ : Found $\left(\mathrm{M}+\mathrm{Na}^{+}\right)$: 503.2230; IR $\left(\mathrm{cm}^{-1}\right)$ : $3075(\mathrm{w}), 3054(\mathrm{w}), 2931(\mathrm{~m})$, $2857(\mathrm{~m}), 1773(\mathrm{~s}), 1471(\mathrm{~m}), 1427(\mathrm{~m}), 130(\mathrm{~m}), 1188(\mathrm{~m}), 1110(\mathrm{~s}), 1073(\mathrm{~m}), 1048(\mathrm{~m}), 914$ $(\mathrm{m}), 823(\mathrm{~m}), 738(\mathrm{~m}), 702(\mathrm{~s}) ;[\alpha]_{D}{ }^{20}=-4.5^{\circ}\left(\mathrm{c}=1.06, \mathrm{CHCl}_{3}\right)$

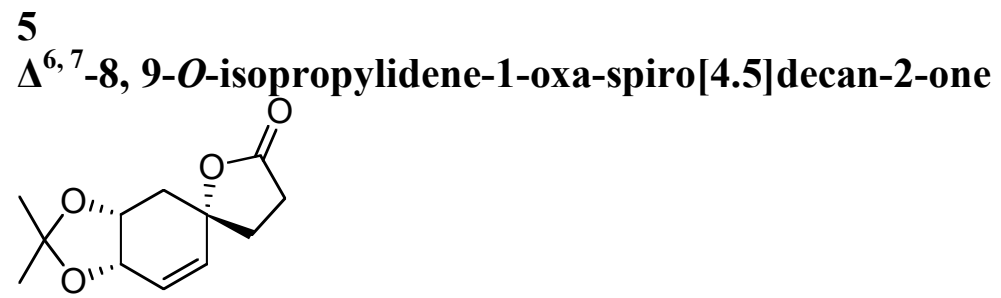

The 7-Methanesulfonyloxy-8, 9-O-isopropylidene-1-oxa-spiro[4.5]decan-2-one ( $1.55 \mathrm{~g}, 4.83$ mmol) and DBU (7.22 ml, $48.3 \mathrm{mmol})$ was added to $42 \mathrm{ml}$ toluene to form a suspension in microwave tube. The suspension was heated up to $150^{\circ} \mathrm{C}$ in about $15 \mathrm{~min}$. in microwave and hold at this temperature for $20 \mathrm{~min}$. The brown color solution was then cooled down to rt and diluted with toluene. Then solution was then washed with $5 \% \mathrm{HCl}$ aqueous solution, saturated $\mathrm{NaHCO}_{3}$ solution and brine in sequence, dried with $\mathrm{Na}_{2} \mathrm{SO}_{4}$ and concentrated under vacuum. The crude product was purified by column chromatography $\left(50 \%\right.$ EtOAc $/ 50 \%$ hexanes, $\left.R_{\mathrm{f}} 0.39\right)$ to give white crystals $11(0.88 \mathrm{~g}, 81 \%) .{ }^{1} \mathrm{H}$ NMR $(\mathrm{CDCl} 3): \delta 6.00-5.90(2 \mathrm{H}, \mathrm{m}), 4.49(1 \mathrm{H}, \mathrm{dd}, J$ $=2.6,5.8 \mathrm{~Hz}), 4.39-4.31(1 \mathrm{H}, \mathrm{m}), 2.65-2.60(2 \mathrm{H}, \mathrm{m}), 2.18-2.04(4 \mathrm{H}, \mathrm{m}), 1.48(3 \mathrm{H}, \mathrm{s}), 1.38(3$ $\mathrm{H}, \mathrm{s}) ;{ }^{13} \mathrm{C} \mathrm{NMR}\left(\mathrm{CDCl}_{3}\right): \delta 175.9,133.6,126.3,110.3,82.7,71.4,70.0,36.7,33.0,28.3,28.0$, 26.0; HRMS (ESI) calculated for $\mathrm{C}_{12} \mathrm{H}_{16} \mathrm{O}_{4}$, Found $\left(\mathrm{M}+\mathrm{H}^{+}\right): 225.1120 ; \operatorname{IR}\left(\mathrm{cm}^{-1}\right): 3036(\mathrm{w})$, 2985 (m), 2935 (m), $2874(\mathrm{~m}), 1774(\mathrm{~m}), 1457(\mathrm{~m}), 1422(\mathrm{~m}), 1400(\mathrm{~m}), 1381(\mathrm{~m}), 1372(\mathrm{~m})$, 1296 (m), 1240 (s), 1218 (s), 1189 (s), 1153 (s), 1066 (s), 1026 (s), 912 (m), 869 (m), 797 (m); $[\alpha]_{D}^{20}=44.6^{\circ}\left(\mathrm{c}=0.84, \mathrm{CHCl}_{3}\right) ; \mathrm{mp}: 99-100^{\circ} \mathrm{C}$

6

3-Hydroxyl- $\Delta^{6,7}$-8, 9-O-isopropylidene-1-oxa-spiro[4.5]decan-2-one

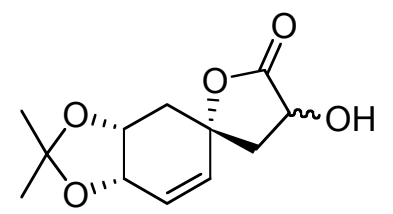

To a solution containing KHMDS (13.38 ml, $0.5 \mathrm{M}$ solution in toluene) in $50 \mathrm{ml}$ dry THF which was cooled down to $-78^{\circ} \mathrm{C}$, was added dropwise to a solution containing compound $5(0.50 \mathrm{~g}, 2.2$ mmol) while stirring, the solution turned dark blue gradually. The solution was allowed to stir at $-78^{\circ} \mathrm{C}$ for $0.5 \mathrm{~h}$, then Molybdenum pentaoxide $\cdot$ HMPA $\cdot$ Pyridine complex (MoOPH $1.94 \mathrm{~g}, 4.5$ mmol) was added all at once. The reaction mixture was allowed to gradually warm up to rt and stirred for $2 \mathrm{~h}$. The reaction was then quenched with Sat. $\mathrm{Na}_{2} \mathrm{SO}_{3}$ aqueous solution and the organic layer was separated. The aqueous layer was saturated with $\mathrm{NaCl}$ and extracted 4 times with EtOAc. The organic layers were combined, washed with brine, dried with $\mathrm{Na}_{2} \mathrm{SO}_{4}$ and concentrated under vacuum. The crude product was purified by column chromatography $(50 \%$ 
EtOAc $/ 50 \%$ hexanes, $R_{f} 0.17$ ) to give a mixture of inseparable two diastereomers 12 (colorless oil, $0.36 \mathrm{~g}, 67 \%) .{ }^{1} \mathrm{H}$ NMR (CDCl3): $\delta$ 6.00-5.83 (2 H, m), 4.68-4.60 (1 H, m), 4.52-4.48 (1 H, $\mathrm{m}), 4.43-4.34$ (1 H, m), $3.60(1 \mathrm{H}, \mathrm{b}), 2.56-2.44,2.36-2.30$ (1 H, m, diastereomeric), 2.23-2.00 (3 $\mathrm{H}, \mathrm{m}), 1.48(3 \mathrm{H}, \mathrm{s}), 1.38(3 \mathrm{H}, \mathrm{s}){ }^{13} \mathrm{C} \mathrm{NMR}\left(\mathrm{CDCl}_{3}\right)$, (two sets): $\delta 177.0,176.9,134.0,131.4$, $128.1,126.8,110.5,110.3,80.5,79.8,71.4,71.0,69.9,67.6,67.5,42.5,40.5,37.8,36.5,28.0$, 27.9, 26.1, 26.0; HRMS (ESI) calculated for $\mathrm{C}_{12} \mathrm{H}_{16} \mathrm{O}_{5}$ : Found $\left(\mathrm{M}-\mathrm{Me}^{+}\right): 225.0761$; IR( $\left(\mathrm{cm}^{-1}\right)$ : 3418 (m, b), 2985 (m), 2926 (m), 2858 (m), 1773 (s), 1456 (m), 1383 (m), 1372 (m), 1240 (s), $1206(\mathrm{~s}), 1123(\mathrm{~m}), 1066(\mathrm{~m}), 900(\mathrm{w}), 946(\mathrm{~m}), 867(\mathrm{~m}), 762(\mathrm{w})$

7

5-[3-(tert-Butyl-diphenyl-silanyloxy)-2-hydroxy-propyl]-2,2-dimethyl-3a,4,5,7a-tetrahydrobenzo[1,3]dioxol-5-ol<smiles>CC1(C)O[C@H]2C=C[C@](O)(C[C@@H](O)C[O+3])C[C@H]2O1</smiles>

The $\alpha$-hydroxyl-lactone $6(0.17 \mathrm{~g}, 0.69 \mathrm{mmol})$ was dissolved in $10 \mathrm{ml}$ absolute $\mathrm{EtOH}$ and then $\mathrm{NaBH}_{4}(52 \mathrm{mg}, 1.38 \mathrm{mmol})$ and $\mathrm{LiCl}(58 \mathrm{mg}, 1.38 \mathrm{mmol})$ were added all at once while stirring. After $1 \mathrm{~h}$, the reaction was quenched with saturated $\mathrm{NH}_{4} \mathrm{Cl}$ aqueous solution then diluted with EtOAc. The mixture was kept stirring until all the precipitate dissolved. The organic layer was separated and the aqueous layer was saturated with $\mathrm{NaCl}$ and extracted with EtOAc five times. The organic phase was dried with with $\mathrm{Na}_{2} \mathrm{SO}_{4}$ and concentrated under vacuum to give foam-like solids. Without further purification, the crude product was then dissolved in dry $10 \mathrm{ml} \mathrm{CH}_{2} \mathrm{Cl}_{2}$ at $0^{\circ} \mathrm{C}$. Imidazole $(93.9 \mathrm{mg}, 1.38 \mathrm{mmol})$ and TBDPSCl $(0.18 \mathrm{ml}, 0.69 \mathrm{mmol})$ was then added to the solution in sequence. The reaction mixture was allowed to warm up to rt and stirred over night. The reaction was then quenched with saturated $\mathrm{NH}_{4} \mathrm{Cl}$ aqueous solution and the organic layer was separated. The aqueous layer was extracted twice with EtOAc. The organic layers were combined, washed with brine, dried with $\mathrm{Na}_{2} \mathrm{SO}_{4}$ and concentrated under vacuum. The crude product was purified by column chromatography $\left(30 \%\right.$ EtOAc/70\% Hexanes, $\left.R_{\mathrm{f}} 0.37\right)$ to give two inseparable diastereomers 16 (colorless oil, $0.28 \mathrm{~g}, 85 \%$ for two steps). ${ }^{1} \mathrm{H}$ NMR (CDCl3): $\delta$ 7.68-7.62 (4 H, m), 7.45-7.34 (6 H, m), 5.93 and $5.80(1 \mathrm{H}, \mathrm{d}, J=10.2 \mathrm{~Hz}$, diastereomeric), 5.68$5.60(1 \mathrm{H}, \mathrm{m}$, diastereomeric), 4.53-4.44 (2 H, m), 4.15-4.00 (1 H, m), 3.68-3.50 (2 H, m), 2.49$2.28(1 \mathrm{H}, \mathrm{m}), 2.02-1.89(1 \mathrm{H}, \mathrm{m}), 1.74-1.61(2 \mathrm{H}, \mathrm{m}), 1.45(3 \mathrm{H}, \mathrm{s}), 1.37$ and $1.36(3 \mathrm{H}, \mathrm{s}$, diastereomeric), $1.06(9 \mathrm{H}, \mathrm{s}) ;{ }^{13} \mathrm{C} \mathrm{NMR}\left(\mathrm{CDCl}_{3}\right)$ : (two sets) $\delta 135.5,134.6,134.0,133.3,133.2$, $129.7,127.8,126.0,125.7,109.7,109.6,73.2,73.1,72.1,71.9,68.8,68.6,68.4,68.0,44.0,43.9$, $36.9,35.0,28.1,26.8,26.5,26.4,19.2$; HRMS (ESI) calculated for $\mathrm{C}_{28} \mathrm{H}_{38} \mathrm{O}_{5} \mathrm{Si}$, Found (M + $\left.\mathrm{Na}^{+}\right): 505.2395 ; \operatorname{IR}\left(\mathrm{cm}^{-1}\right): 3061(\mathrm{w}), 2982(\mathrm{w}), 2931(\mathrm{~m}), 2856(\mathrm{~m}), 1427(\mathrm{~m}), 1380(\mathrm{~m}), 1236$ (m), 1223 (m), 1162 (m), 1112 (s), 1041 (m), 885 (w), 824 (m), 740 (m), 702 (s).

\section{8}

1-(tert-Butyl-diphenyl-silanyloxy)-3-(2-hydroxy-5,5-dimethyl-hexahydro-1,4,6-trioxacyclopropa[e]inden-2-yl)-propan-2-one<smiles>CC1(C)O[C@H]2CC(O)(CC(=O)CO[Sb])C3OC3[C@H]2O1</smiles>

The diatereomeric epoxide $7(23 \mathrm{mg}, 0.046 \mathrm{mmol})$ was dissolved in $2 \mathrm{ml}$ dry $\mathrm{CH}_{2} \mathrm{Cl}_{2}$ then $\mathrm{NaHCO}_{3}(20 \mathrm{mg}, 0.23 \mathrm{mmol})$ and Dess-Martin Reagent $(39 \mathrm{mg}, 0.092 \mathrm{mmol})$ were added in sequence. The reaction completed in $0.5 \mathrm{~h}$. The reaction was then quenched with saturated $\mathrm{Na}_{2} \mathrm{SO}_{3}$ aqueous solution and the organic layer was separated. The aqueous layer was extracted twice with EtOAc. The organic layers were combined, washed with brine, dried with $\mathrm{Na}_{2} \mathrm{SO}_{4}$ 
and concentrated under vacuum. The crude product was purified by column chromatography (30\% EtOAc/70\% Hexanes, $R_{f} 0.44$ ) to give a single diastereomer 20 (colorless oil, $20 \mathrm{mg}$, 87\%). ${ }^{1} \mathrm{H}$ NMR (CDCl3): $\delta$ 7.71-7.60 (4 H, m), 7.45-7.29 (4 H, m), 4.40-4.23 (4 H, m), $3.91(1$ $\mathrm{H}, \mathrm{s}), 3.21(1 \mathrm{H}, \mathrm{d}, J=3.6 \mathrm{~Hz}), 3.10(1 \mathrm{H}, \mathrm{dd}, J=1.2,3.6 \mathrm{~Hz}), 2.62(1 \mathrm{H}, \mathrm{d}, J=3.6 \mathrm{~Hz}), 2.59(1$ $\mathrm{H}, \mathrm{d}, J=3.6 \mathrm{~Hz}), 2.01-1.95(1 \mathrm{H}, \mathrm{m}), 1.73(1 \mathrm{H}, \mathrm{dd}, \mathrm{J}=2.0,5.6 \mathrm{~Hz}), 1.47(3 \mathrm{H}, \mathrm{s}), 1.35(3 \mathrm{H}, \mathrm{s})$, $1.11(9 \mathrm{H}, \mathrm{s}) ;{ }^{13} \mathrm{C}$ NMR $\left(\mathrm{CDCl}_{3}\right): \delta 206.3,135.7,135.6,132.9,129.8,127.7,109.2,72.5,71.2$, 70.2, 69.2, 56.9, 53.6, 47.0, 28.7, 27.8, 26.8, 25.3, 19.3; HRMS (ESI) calculated for $\mathrm{C}_{28} \mathrm{H}_{36} \mathrm{O}_{6} \mathrm{Si}$ : 496.2281, Found: ; IR( $\left.\mathrm{cm}^{-1}\right): 3490(\mathrm{~b}), 3071(\mathrm{w}), 2985(\mathrm{~m}), 2931(\mathrm{~s}), 2857(\mathrm{~m}), 1730(\mathrm{~s}), 1588$ (w), $1472(\mathrm{~m}), 1428(\mathrm{~s}), 1376(\mathrm{~s}), 1322(\mathrm{w}), 1223(\mathrm{~m}), 1152(\mathrm{~m}), 1113(\mathrm{~s}), 1083(\mathrm{~m}), 938(\mathrm{w})$, $882(\mathrm{~m}), 835(\mathrm{~m}), 741(\mathrm{~m}), 703(\mathrm{~s}) ;[\alpha]_{D}^{20}$ (need to be added)

\section{5}<smiles>O=C1OC2(C=C[C@@H](O)C(O)C2)C[C@H]1O[Mg]</smiles>

The corresponding acetonide $(0.563 \mathrm{~g}, 1.18 \mathrm{mmol})$ was dissolved in a round-bottom flask containing $21 \mathrm{ml} \mathrm{AcOH} / \mathrm{THF} / \mathrm{H}_{2} \mathrm{O}$ (3:2:2 volume ratio). The flask was then immersed into an oil bath which was pre-equilibrated at $45^{\circ} \mathrm{C}$ under the protection of Ar. The reaction mixture was heated at $45^{\circ} \mathrm{C}$ for $8 \mathrm{~h}$. Then the reaction was cooled to rt, neutralized with $\mathrm{NaHCO}_{3}$, extracted with EtOAc, and washed with brine. The crude product was purified by column chromatography ( $50 \%$ EtOAc/hexanes, $\mathrm{R}_{f} 0.25$ ) to give $0.42 \mathrm{~g}$ pure colorless oil as two inseparable diastereomers, while $0.11 \mathrm{~g}$ starting material was recovered.(Yield: $81 \%$, but almost quantitative based on recovered starting material). ${ }^{1} \mathrm{H}$ NMR $(\mathrm{CDCl} 3)$ : $\delta$ 7.79-7.77 $(2 \mathrm{H}, \mathrm{m}), 7.68-7.66(2 \mathrm{H}$, m), 7.48-7.37 (6 H, m), 5.93 (dd, J = 3.6, $10.2 \mathrm{~Hz}), 5.83(\mathrm{~d}, \mathrm{~J}=10.1 \mathrm{~Hz}), 5.79$ (dd, J = 2.9, 10.1 $\mathrm{Hz}), 5.45(\mathrm{~d}=10.1 \mathrm{~Hz})$ (from 5.93 to 5.45 , totally $2 \mathrm{H}), 4.51-4.46(1 \mathrm{H}, \mathrm{m}), 4.11-4.03(1 \mathrm{H}, \mathrm{m})$, $3.92(\mathrm{~m}), 3.75-3.71(\mathrm{~m})$ (from 53.92 to 3.71 , totally $1 \mathrm{H}), 2.63(2 \mathrm{H}, \mathrm{br}), 2.41(\mathrm{dd}, \mathrm{J}=7.1,14.3$ $\mathrm{Hz}$ ), 2.15-2.00 (m) (from 2.41 to 2.0 , totally $3 \mathrm{H}), 1.73(1 \mathrm{H}, \mathrm{dd}, \mathrm{J}=2.8,13.6 \mathrm{~Hz}), 1.10(9 \mathrm{H}, \mathrm{s})$; ${ }^{13} \mathrm{C}$ NMR $\left(\mathrm{CDCl}_{3}\right): \delta 174.0,173.9,135.9,135.6,132.9,132.2,131.9,131.8,131.3,130.2,129.1$, 127.9, 127.8, 79.5, 78.9, 68.8, 68.7, 66.5, 66.4, 66.3, 65.8, 43.5, 42.8, 39.4, 37.7, 26.6, 19.1; HRMS (ESI) calculated for $\mathrm{C}_{25} \mathrm{H}_{30} \mathrm{O}_{5} \mathrm{Si}$ : 438.1863, Found $\left(\mathrm{M}+\mathrm{Na}^{+}\right)$: 461.1752; $\mathrm{IR}\left(\mathrm{cm}^{-1}\right)$ : 3395(m, b), 3072 (w), 3040 (w), 2932 (m), $2858(\mathrm{~m}), 1784(\mathrm{~s}), 1589$ (w), $1472(\mathrm{~m}), 1428(\mathrm{~s})$, $1255(\mathrm{~m}), 1152(\mathrm{~s}), 1112(\mathrm{~s}), 1030(\mathrm{~m}), 911(\mathrm{~m}), 823(\mathrm{~m}), 737(\mathrm{~m}), 702(\mathrm{~s})$

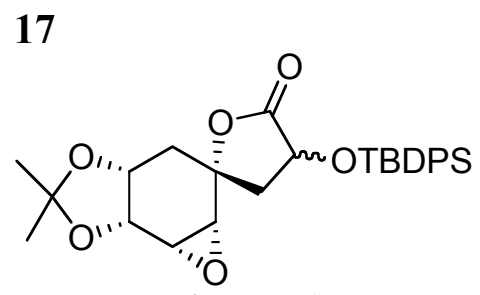

Compound $16(0.118 \mathrm{~g}, 0.26 \mathrm{mmol})$ was dissolved in $5 \mathrm{ml}$ acetone then $1 \mathrm{ml} \mathrm{2,2-}$ dimethoxypropane and $5.2 \mathrm{mg} \mathrm{TsOH} \cdot \mathrm{H}_{2} \mathrm{O}(0.026 \mathrm{mmol})$ were added in sequence. The mixture was stirred at $\mathrm{rt}$ and monitored by TLC until the reaction completed. The reaction was quenched with saturated $\mathrm{NaHCO}_{3}$ solution, extracted with EtOAc. The organic layer was separated, washed with brine and dried with $\mathrm{Na}_{2} \mathrm{SO}_{4}$. The crude product was concentrated and purified by column chromatography ( $30 \%$ EtOAc / Hexanes, $R_{f} 0.39$ and 0.385$)$ to give a mixture of two diastereomers that were not separated. ${ }^{1} \mathrm{H}$ NMR $\left(\mathrm{CDCl}_{3}\right): \delta 7.80-7.76(2 \mathrm{H}, \mathrm{m}), 7.70-7.66(2 \mathrm{H}$, $\mathrm{m})$, 7.50-7.39 (6 H, m), 4.52-4.43 (1 H, m), 4.34-4.30 (1 H, m), 4.12-4.07 (m), 3.95-3.89 (m) (these two sets of peaks added up to $1 \mathrm{H}), 3.49(\mathrm{dd}, J=3.2,3.9 \mathrm{~Hz}), 3.40-3.39(\mathrm{~m}), 3.00(\mathrm{~d}, J=$ $3.2 \mathrm{~Hz}), 2.27(0.5 \mathrm{H}$ dd, $J=11.3,11.7 \mathrm{~Hz}), 2.12-1.90(3 \mathrm{H}, \mathrm{m}), 1.60(0.5 \mathrm{H}, \mathrm{dd}, J=12.3,12.7$ 
$\mathrm{Hz}), 1.52$ and $1.48(3 \mathrm{H}, \mathrm{s}), 1.33$ and $1.30(3 \mathrm{H}, \mathrm{s}), 1.102$ and $1.100(9 \mathrm{H}, \mathrm{s}) ;{ }^{13} \mathrm{C} \mathrm{NMR}\left(\mathrm{CDCl}_{3}\right)$ (theoretically two sets): $\delta 173.5,135.9,135.8,135.6,132.9,131.5,130.3,127.9,127.8,109.8$, 81.7, 81.2, 71.4, 71.3, 69.0, 68.6, 56.9, 56.4, 56.1, 52.1, 52.0, 39.1, 38.0, 35.6, 34.1, 27.1, 27.0, 25.2, 24.9, 24.8, 19.1; HRMS (ESI) calculated for $\mathrm{C}_{28} \mathrm{H}_{34} \mathrm{O}_{6} \mathrm{Si}$ : 494.2125 , Found $\left(\mathrm{M}+\mathrm{Na}^{+}\right)$: 617.2003; IR ( $\left.\mathrm{cm}^{-1}\right): 3072(\mathrm{w}), 2933(\mathrm{~m}), 2858(\mathrm{~m}), 1787(\mathrm{~s}), 1588(\mathrm{w}), 1472(\mathrm{~m}), 1427(\mathrm{~s}), 1381$ (m), $1370(\mathrm{~m}), 1259(\mathrm{~m}), 1211(\mathrm{~m}), 1145(\mathrm{~s}), 1112(\mathrm{~s}), 1068(\mathrm{~m}), 1009(\mathrm{~m}), 914(\mathrm{~m}), 856(\mathrm{~m})$, $822(\mathrm{~m}), 743(\mathrm{~m}), 702(\mathrm{~s})$

\section{8}

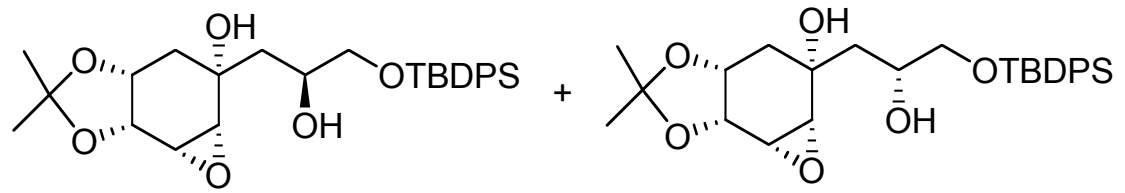

Compound 24 (0.196 g, $0.40 \mathrm{mmol})$ was dissolved in $10 \mathrm{ml} \mathrm{EtOH}$ and the solution was cooled to $-15^{\circ} \mathrm{C} . \mathrm{CeCl}_{3}(0.391 \mathrm{~g}, 1.59 \mathrm{mmol})$ was added all at once to the solution and stirred for $10 \mathrm{~min}$. $\mathrm{NaBH}_{4}(60 \mathrm{mg}, 1.59 \mathrm{mmol})$ was then added and the mixture was stirred around $-15^{\circ} \mathrm{C}$ for 30 min. The reaction was then quenched with saturated $\mathrm{NH}_{4} \mathrm{Cl}$ solution and extracted with EtOAc. The organic phase was washed with brine and dried over $\mathrm{Na}_{2} \mathrm{SO}_{4}$. The four diastereomeric lactols obtained $(0.156 \mathrm{~g})$ were concentrated and dried under vacuum without further separation. The crude product was dissolved in $10 \mathrm{ml}$ EtOH at $0^{\circ} \mathrm{C}$ and excess $\mathrm{NaBH}_{4}$ was added. The reaction was monitored by TLC until all the starting materials were consumed. The reaction was then quenched with saturated $\mathrm{NH}_{4} \mathrm{Cl}$ solution and extracted with EtOAc. The organic phase was washed with brine and dried over $\mathrm{Na}_{2} \mathrm{SO}_{4}$. The two diasteremoers $(0.150 \mathrm{~g}, 0.30 \mathrm{mmol})$ were separated by column chromatography (30\% EtOAc / hexanes, $R_{f}=0.15$ (25a), 0.13 (25b) ). (75\% yield for two steps). 25a: ${ }^{1} \mathrm{H}$ NMR (CDCl3): $\delta$ 7.67-763 (4 H, m), 7.47-7.37 (6 H, m), 4.34 (1 H, dd, J = 3.0, 7.4 Hz), 4.24-4.18 (1 H, m), 4.17-4.12 (1 H, m), 3.63- 3.55 (2 H, m), 3.43 $(1 \mathrm{H}$, dd (looked like t), $\mathrm{J}=3.6,3.9 \mathrm{~Hz}), 3.30(1 \mathrm{H}, \mathrm{d}, \mathrm{J}=4.0 \mathrm{~Hz}), 3.16(1 \mathrm{H}, \mathrm{b}), 1.98-1.88(2 \mathrm{H}$, m), $1.60(2 \mathrm{H}, \mathrm{d}, \mathrm{J}=6.2 \mathrm{~Hz}), 1.53(3 \mathrm{H}, \mathrm{s}), 1.33(3 \mathrm{H}, \mathrm{s}), 1.07(9 \mathrm{H}, \mathrm{s}) ;{ }^{13} \mathrm{C} \mathrm{NMR}\left(\mathrm{CDCl}_{3}\right): \delta$ $135.5,133.0,132.9,129.9,127.8,109.3,71.9,71.5,71.2,68.5,68.0,59.0,53.5,40.0,37.3,26.9$, 26.8, 24.8, 19.2; HRMS (ESI) calculated for $\mathrm{C}_{28} \mathrm{H}_{38} \mathrm{O}_{6} \mathrm{Si}: 498.2438$, Found $\left(\mathrm{M}+\mathrm{Na}^{+}\right)$: 521.2279; IR ( $\left.\mathrm{cm}^{-1}\right): 3440(\mathrm{~m}, \mathrm{~b}), 3070(\mathrm{w}), 3048(\mathrm{w}), 2931(\mathrm{~m}), 2858(\mathrm{~m}), 1589(\mathrm{w}), 1472(\mathrm{~m}), 1462(\mathrm{~m})$, $1428(\mathrm{~s}), 1381(\mathrm{~m}), 1258(\mathrm{~m}), 1209(\mathrm{~m}), 1112(\mathrm{~s}), 1055(\mathrm{~s}), 966(\mathrm{w}), 912(\mathrm{~m}), 834(\mathrm{~m}), 740(\mathrm{~m})$, $703(\mathrm{~s}),[\alpha]_{D}{ }^{23}=18.2^{\circ}\left(\mathrm{c}=1.84, \mathrm{CHCl}_{3}\right) ; 25 \mathrm{~b}:{ }^{1} \mathrm{H} \mathrm{NMR}(\mathrm{CDCl} 3): \delta$ 7.66-7.63 (4 H, m), 7.477.37 (6 H, M), $4.32(1 \mathrm{H}, \mathrm{dd}, \mathrm{J}=3.0,7.3 \mathrm{~Hz}), 4.16-4.11(1 \mathrm{H}, \mathrm{m}), 4.06(1 \mathrm{H}, \mathrm{dd}, \mathrm{J}=7.5,15.8$ $\mathrm{Hz}), 3.63-3.55(1 \mathrm{H}, \mathrm{m}), 3.43(1 \mathrm{H}$, dd (looked like t), J=3.3, $4.0 \mathrm{~Hz}), 3.31(1 \mathrm{H}, \mathrm{d}, \mathrm{J}=4.1 \mathrm{~Hz})$, $3.21(1 \mathrm{H}, \mathrm{b}), 1.98-1.95(2 \mathrm{H}, \mathrm{m}), 1.69(1 \mathrm{H}, \mathrm{dd}, \mathrm{J}=10.2,15.6 \mathrm{~Hz}), 1.53(3 \mathrm{H}, \mathrm{s}), 1.49(1 \mathrm{H}, \mathrm{dd}, \mathrm{J}$ $=1.9,14.6 \mathrm{~Hz}), 1.31(3 \mathrm{H}, \mathrm{s}), 1.07(9 \mathrm{H}, \mathrm{s}) ;{ }^{13} \mathrm{C} \mathrm{NMR}\left(\mathrm{CDCl}_{3}\right): \delta 135.5,133.0,129.91,129.90$, $127.8,109.3,71.8,71.4,68.8,67.8,59.5,53.0,38.7,35.8,26.9,26.8,24.7,19.2$; HRMS (ESI) calculated for $\mathrm{C}_{28} \mathrm{H}_{38} \mathrm{O}_{6} \mathrm{Si}$ : 498.2438, Found $\left(\mathrm{M}+\mathrm{Na}^{+}\right): 521.2326 \mathrm{IR}\left(\mathrm{cm}^{-1}\right): 3441(\mathrm{~m}, \mathrm{~b}), 3070$ (w), $3048(\mathrm{w}), 2931(\mathrm{~m}), 2858(\mathrm{~m}), 1588(\mathrm{w}), 1472(\mathrm{~m}), 1462(\mathrm{~m}), 1428(\mathrm{~s}), 1381(\mathrm{~m}), 1258(\mathrm{~m})$, $1209(\mathrm{~m}), 1112(\mathrm{~s}), 1055(\mathrm{~s}), 966(\mathrm{w}), 912(\mathrm{~m}), 834(\mathrm{~m}), 740(\mathrm{~m}), 703(\mathrm{~s}),[\alpha]_{D}{ }^{23}=17.4(\mathrm{c}=1.65$ $\left.\mathrm{CHCl}_{3}\right)$ 
19<smiles>CC1(C)O[C@@H]2C(=O)CC(O)(CC(=O)CO[Pb])C[C@H]2O1</smiles>

Compound 18 (47.7 mg, $0.096 \mathrm{mmol}$ ) was dissolved in $2 \mathrm{ml}$ dry $\mathrm{CH}_{2} \mathrm{Cl}_{2}$ then $\mathrm{NaHCO}_{3}(40 \mathrm{mg}$, $0.48 \mathrm{mmol}$ ) and Dess-Martin reagent $(162 \mathrm{mg}, 0.38 \mathrm{mmol})$ were added in sequence. The mixture was stirred at $\mathrm{rt}$ and monitored by TLC until the reaction completed. The mixture was quenched with saturated $\mathrm{Na}_{2} \mathrm{SO}_{3}$ solution, extracted with EtOAc. The organic layers were combined, washed with brine and dried with $\mathrm{Na}_{2} \mathrm{SO}_{4}$. The crude product was concentrated and purified by column chromatography ( $30 \%$ EtOAc / Hexanes, $R_{f} 0.27$ ) to give a colorless oil (43.3 mg, 0.087 mmol, 90\%). ${ }^{1} \mathrm{H}$ NMR $\left(\mathrm{CDCl}_{3}\right): \delta$ 7.66-7.63 $(4 \mathrm{H}, \mathrm{m}), 7.48-7.37(6 \mathrm{H}, \mathrm{m}), 4.34(1 \mathrm{H}, \mathrm{dd}, J=3.0$, $7.2 \mathrm{~Hz}), 4.25(2 \mathrm{H}, \mathrm{s}), 4.11(1 \mathrm{H}, \mathrm{m}), 3.40(1 \mathrm{H}, \mathrm{dd}$ (looked like t), $J=3.2,4.0 \mathrm{~Hz}), 3.30(1 \mathrm{H}, \mathrm{s})$, $3.25(1 \mathrm{H}, \mathrm{d}, J=4.0 \mathrm{~Hz}), 2.74$ and $2.68(2 \mathrm{H}, \mathrm{d}, J=16.4 \mathrm{~Hz}), 1.93-1.84(2 \mathrm{H}, \mathrm{m}), 1.53(3 \mathrm{H}, \mathrm{s})$, $1.32(3 \mathrm{H}, \mathrm{s}), 1.11(9 \mathrm{H}, \mathrm{s}) ;{ }^{13} \mathrm{C}$ NMR $\left(\mathrm{CDCl}_{3}\right): \delta 208.6,135.53,135.51,132.4,132.3,130.1$, 127.9, 109.4, 71.8, 71.5, 70.5, 70.0, 58.7, 53.2, 45.1, 36.3, 26.9, 26.7, 24.9, 19.2; HRMS (ESI) calculated for $\mathrm{C}_{28} \mathrm{H}_{36} \mathrm{O}_{6} \mathrm{Si}: 496.2281$, Found $\left(\mathrm{M}+\mathrm{Na}^{+}\right)$: 519.2185; IR $\left(\mathrm{cm}^{-1}\right): 3446(\mathrm{~m}, \mathrm{~b}), 3071$ $(\mathrm{w}), 2932(\mathrm{~m}), 2858(\mathrm{~m}), 1726(\mathrm{~s}), 1589(\mathrm{w}), 1473(\mathrm{~m}), 1428(\mathrm{~s}), 1382(\mathrm{~m}), 1259(\mathrm{~m}), 1210(\mathrm{M})$, $1164(\mathrm{~m}), 1113(\mathrm{~s}), 1056(\mathrm{~s}), 909(\mathrm{~m}), 824(\mathrm{~m}), 740(\mathrm{~m}), 704(\mathrm{~s}) ;[\alpha]_{D}^{23}=14.1\left(\mathrm{c}=1.71 \mathrm{CHCl}_{3}\right)$

\section{0a}<smiles>CC1(C)O[C@H]2CC(O)(C/C(CO[Pb])=N\O)C[C@H]3O[C@H]3[C@H]2O1</smiles>

Compound 19 (43.3 mg, $0.087 \mathrm{mmol}$ ) was dissolved in $1 \mathrm{ml} \mathrm{EtOH}$ at $\mathrm{rt}$. To this stirred solution, was added dropwise $0.5 \mathrm{ml}$ aqueous solution containing $\mathrm{NH}_{2} \mathrm{OH} \cdot \mathrm{HCl}(18.2 \mathrm{mg}, 0.261 \mathrm{mmol})$ and $\mathrm{NaOAc}(21.4 \mathrm{mg}, 0.261 \mathrm{mmol})$. The reaction mixture was stirred at $\mathrm{rt}$ and monitored by TLC until all the starting material was consumed. The mixture was then diluted with $10 \mathrm{ml}$ EtOAc and washed with brine. The organic layer was separated and dried with $\mathrm{Na}_{2} \mathrm{SO}_{4}$. The crude product was purified by column chromatography (30\% EtOAc / Hexanes) to give two separable oximes as colorless oil $27 \mathbf{a}\left(29.0 \mathrm{mg}, 0.057 \mathrm{mmol} R_{f} 0.27\right)$ and $27 \mathbf{b}\left(14.0 \mathrm{mg}, 0.027 \mathrm{mmol}, R_{f} 0.13\right)$ Yield: $96 \%$. 27b could be isomerized back to $27 \mathbf{a}$ at a ratio of $1: 2$ when heated at $45^{\circ} \mathrm{C}$ in EtOH/ $\mathrm{H}_{2} \mathrm{O}$ solution. Compound 27a: ${ }^{1} \mathrm{H}$ NMR $(\mathrm{CDCl} 3)$ : 7.69-7.63 (4 H, m), 7.46-7.38 (6 H, m), 4.40 ( $1 \mathrm{H}, \mathrm{dd}, \mathrm{J}=2.9,7.3 \mathrm{~Hz}), 4.36-4.31$ (1 H, m), 4.30 (2 H, s), $3.61(1 \mathrm{H}, \mathrm{b}), 3.42$ (1 H, dd, looked like t, J = 3.4, $3.7 \mathrm{~Hz}), 3.20(1 \mathrm{H}, \mathrm{d}, \mathrm{J}=4.1 \mathrm{~Hz}), 2.82(1 \mathrm{H}, \mathrm{d}, \mathrm{J}=13.2 \mathrm{~Hz}), 2.68(1 \mathrm{H}, \mathrm{d}, \mathrm{J}$ $=13.2 \mathrm{~Hz}), 1.92-1.88(2 \mathrm{H}, \mathrm{m}) ; 1.53(3 \mathrm{H}, \mathrm{s}), 1.32(3 \mathrm{H}, \mathrm{s}), 1.07(9 \mathrm{H}, \mathrm{s}) ; \delta^{13} \mathrm{C} \mathrm{NMR}\left(\mathrm{CDCl}_{3}\right): \delta$ $155.9,135.6,135.2,132.3,132.2$, 130.0, 129.9, 127.9, 109.2, 72.0, 71.52, 71.49, 66.0, 59.4, 53.6, 37.1, 33.4, 27.0, 26.7, 24.9, 19.2; HRMS (ESI) calculated for $\mathrm{C}_{28} \mathrm{H}_{37} \mathrm{NO}_{6} \mathrm{Si}: 511.2390$, Found (M $\left.+\mathrm{Na}^{+}\right): 534.2309$; IR $\left(\mathrm{cm}^{-1}\right): 3406(\mathrm{~b}, \mathrm{~m}), 3072(\mathrm{w}), 3050(\mathrm{w}), 2933(\mathrm{~m}), 2858(\mathrm{~m}), 1589(\mathrm{w})$, $1472(\mathrm{~m}), 1462$ (m), $1428(\mathrm{~s}), 1381(\mathrm{~m}), 1370(\mathrm{~m}), 1258(\mathrm{~m}), 1211(\mathrm{~m}), 1166(\mathrm{~m}), 1112(\mathrm{~s}), 1051$ (s), $1007(\mathrm{~m}), 940(\mathrm{~m}), 911(\mathrm{~m}), 856(\mathrm{w}), 823(\mathrm{~m}), 737(\mathrm{~s}), 703(\mathrm{~s}) ;[\alpha]_{D}{ }^{23}=10.9(\mathrm{c}=1.00$ $\left.\mathrm{CHCl}_{3}\right)$ 
<smiles></smiles>

A THF solution $(1 \mathrm{ml})$ of the oxime $\mathbf{2 0 a}(20 \mathrm{mg}, 0.039 \mathrm{mmol})$ was added dropwise into a freshly prepared LDA/THF solution (containing $0.086 \mathrm{mmol} \mathrm{LDA}$ ) at $-78^{\circ} \mathrm{C}$. The solution was warmed up to $\mathrm{rt}$ and stirred for around $5 \mathrm{~h}$ until all the starting material was consumed (monitored by TLC). The reaction was quenched with saturated $\mathrm{NH}_{4} \mathrm{Cl}$ solution and the aqueous phase was extracted with EtOAc. The organic layers were combined, washed with brine and dried with $\mathrm{Na}_{2} \mathrm{SO}_{4}$. The crude product was concentrated and purified by column chromatography $(50 \%$ EtOAc / Hexanes, $\left.R_{f} 0.22\right)$ to give a colorless oil $(16.5 \mathrm{mg}, 0.032 \mathrm{mmol}, 83 \%)$. ${ }^{1} \mathrm{H}$ NMR (CDCl3): $\delta$ 7.66-7.64 (4 H, m), 7.47-7.38 (6 H, m), 4.50-4.47 (1 H, m), $4.43(1 \mathrm{H}, \mathrm{dd}, \mathrm{J}=4.2$, $7.2 \mathrm{~Hz}), 4.34(1 \mathrm{H}, \mathrm{d}, \mathrm{J}=12.6 \mathrm{~Hz}), 4.28(1 \mathrm{H}, \mathrm{d}, \mathrm{J}=12.6 \mathrm{~Hz}), 4.09(1 \mathrm{H}, \mathrm{d}, \mathrm{J}=7.6 \mathrm{~Hz}$, overlapped with a weak broad $-\mathrm{OH}$ peak), $3.69(1 \mathrm{H}, \mathrm{dd}, \mathrm{J}=4.2,7.6 \mathrm{~Hz}), 2.47(1 \mathrm{H}, \mathrm{d}, \mathrm{J}=15.8 \mathrm{~Hz}), 2.33(1$ $\mathrm{H}, \mathrm{d}, \mathrm{J}=15.8 \mathrm{~Hz}), 2.12(1 \mathrm{H}, \mathrm{dd}, \mathrm{J}=2.5,15.5 \mathrm{~Hz}), 1.71(1 \mathrm{H}, \mathrm{dd}, \mathrm{J}=3.6,15.5 \mathrm{~Hz}) ; 1.56(3 \mathrm{H}$, s), $1.37(3 \mathrm{H}, \mathrm{s}), 1.07(9 \mathrm{H}, \mathrm{s}) ;{ }^{13} \mathrm{C} \mathrm{NMR}\left(\mathrm{CDCl}_{3}\right): \delta 165.5,135.6,135.5,132.6,132.5,130.0$, 127.9, 109.0, 81.9, 73.2, 72.8, 70.4, 67.2, 64.4, 34.8, 34.4, 26.8, 26.0, 23.5, 19.2; HRMS (ESI) calculated for $\mathrm{C}_{28} \mathrm{H}_{37} \mathrm{NO}_{6} \mathrm{Si}: 511.2390$, Found $\left(\mathrm{M}+\mathrm{Na}^{+}\right)$: 534.2039; IR (cm $\left.{ }^{-1}\right): 3483$ (b, s), 3071 (m), 2931 (s), 2857 (s), 2249 (m), $1627(\mathrm{~m}), 1589(\mathrm{~m}), 1472(\mathrm{~m}), 1383(\mathrm{~m}), 1259(\mathrm{~m}), 1213(\mathrm{~m})$, $1161(\mathrm{~m}), 1113(\mathrm{~s}), 1017(\mathrm{~m}), 913(\mathrm{~m}), 738(\mathrm{~m}), 703(\mathrm{~s}) ;[\alpha]_{D}{ }^{24}=-20.0\left(\mathrm{c}=2.02 \mathrm{CHCl}_{3}\right)$ 


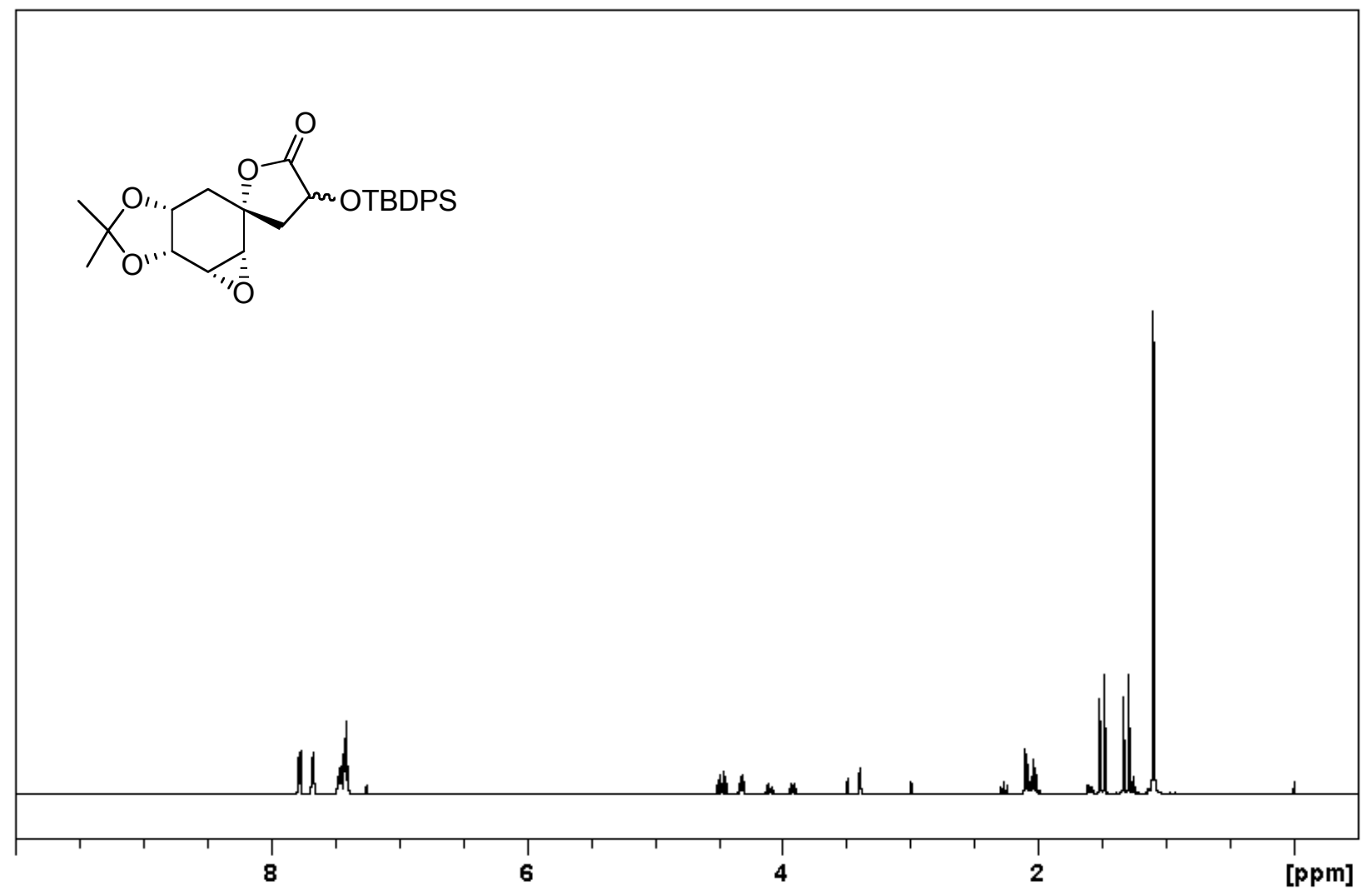

Figure 1: ${ }^{1} \mathrm{H}$ NMR spectrum of compound 17.

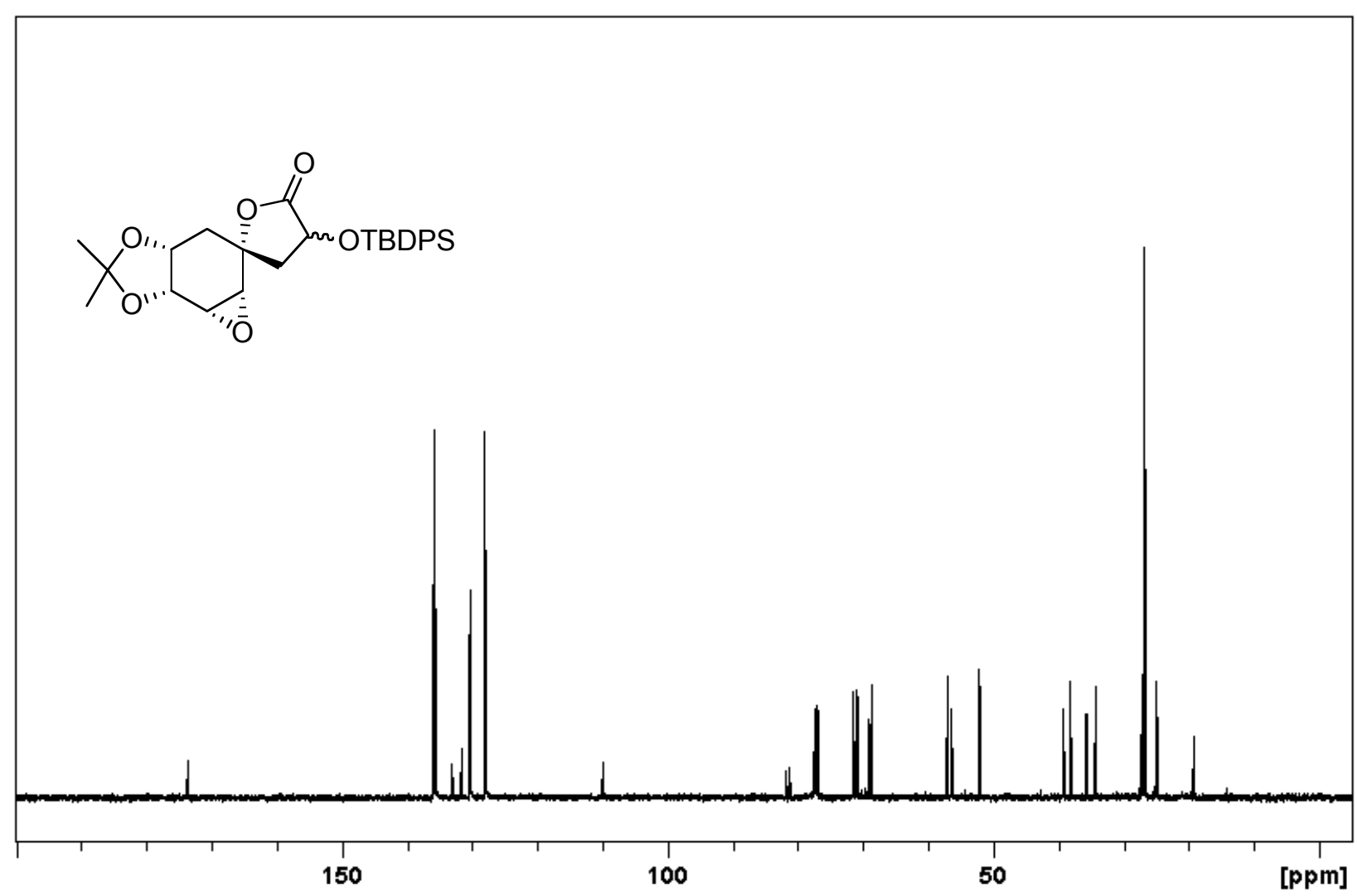

Figure 2: ${ }^{13} \mathrm{C}$ NMR spectrum of compound 17. 


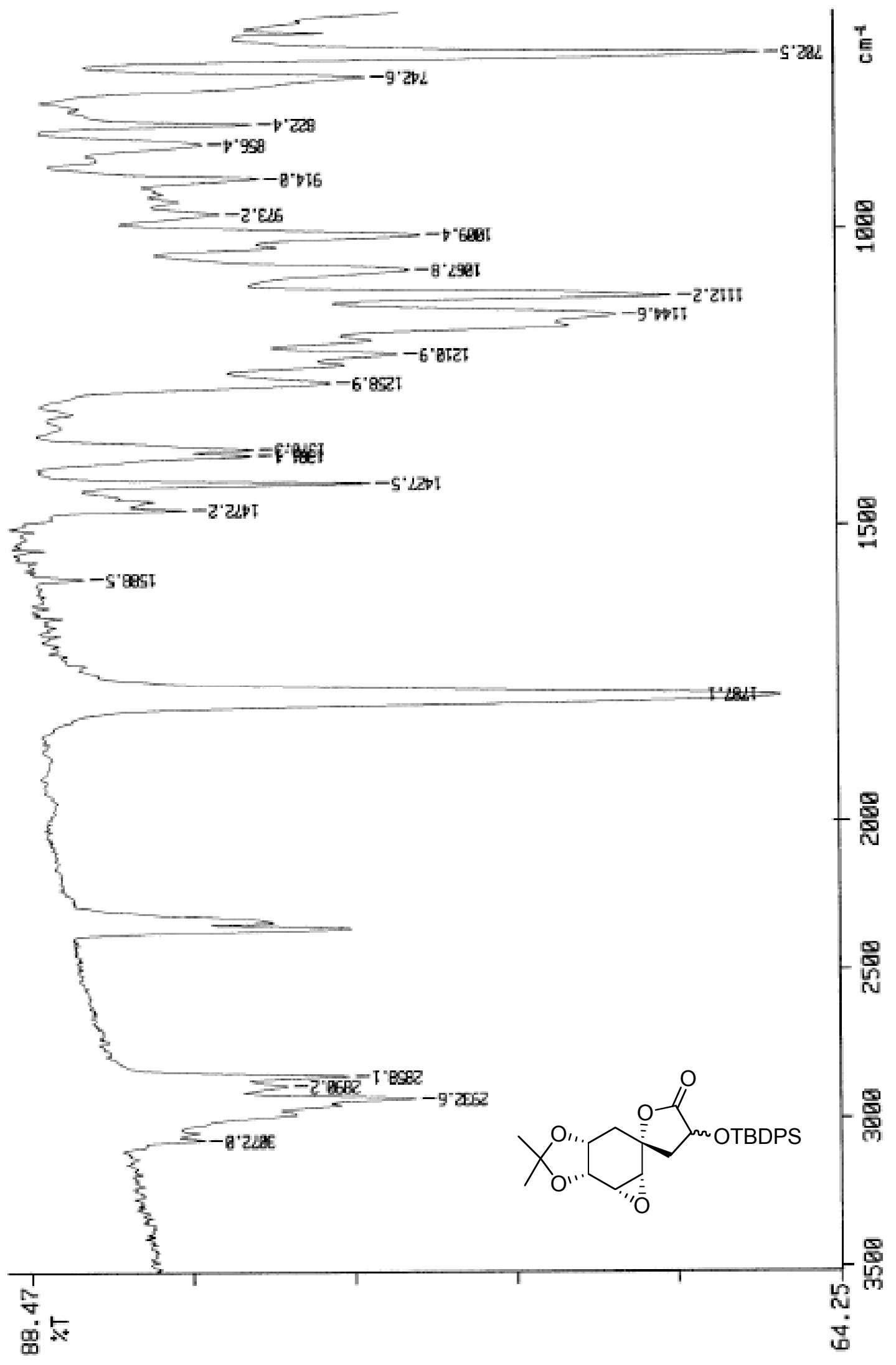

Figure 3: IR spectrum of compound 17. 


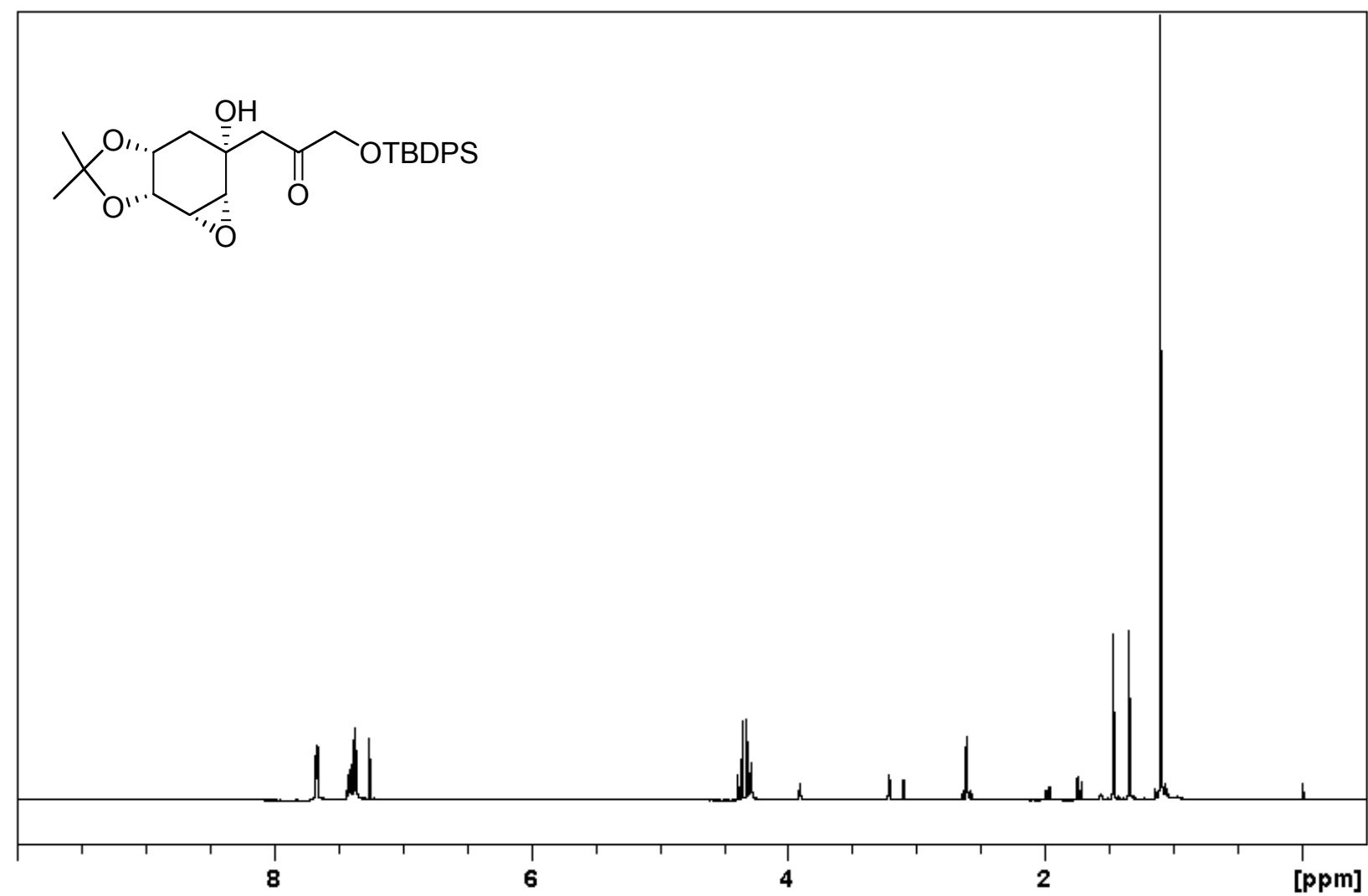

Figure 4: ${ }^{1} \mathrm{H}$ NMR spectrum of compound 19.

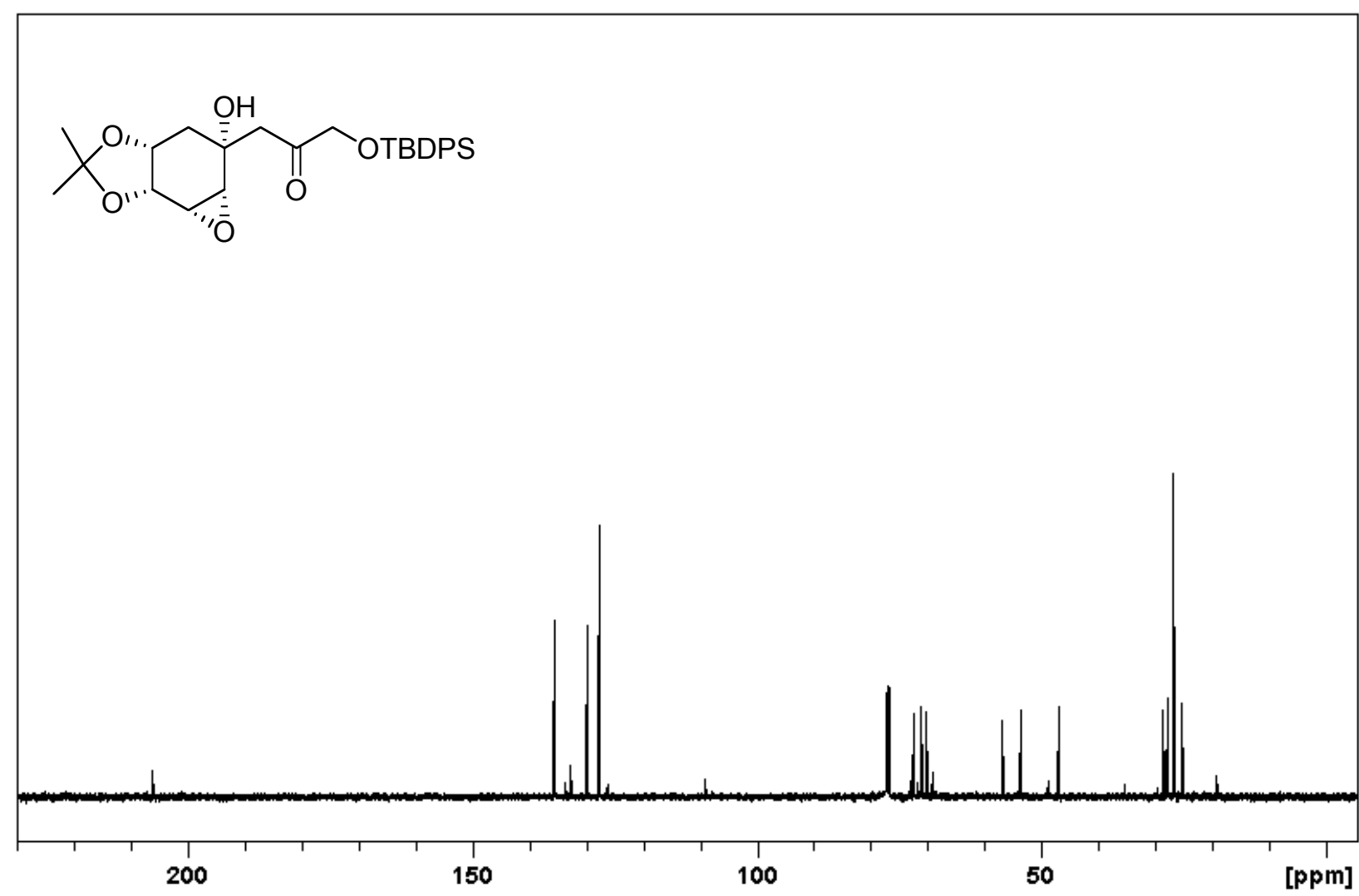

Figure 5: ${ }^{13} \mathrm{C}$ NMR spectrum of compound 19. 


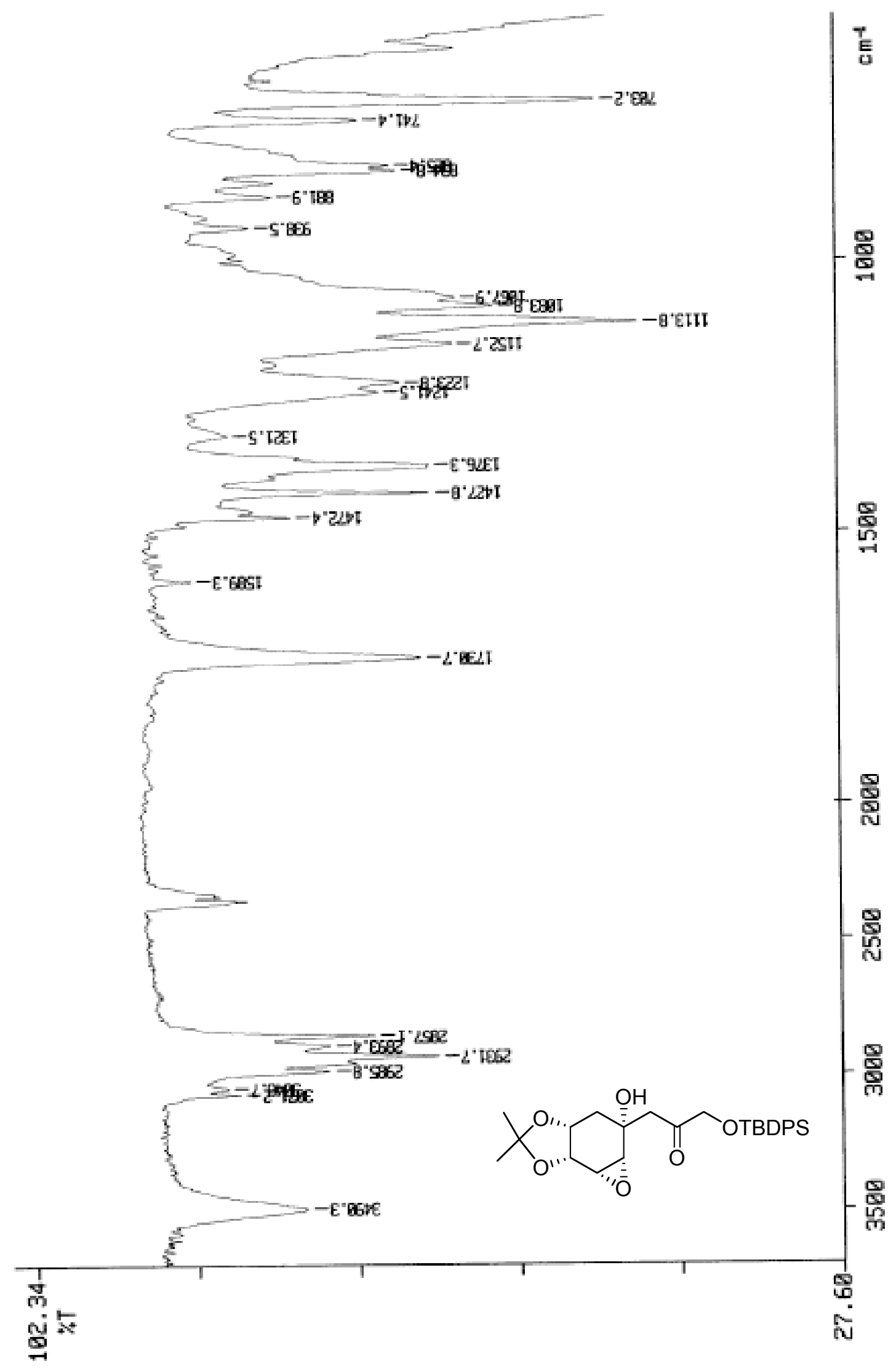

Figure 6: IR spectrum of compound 19. 


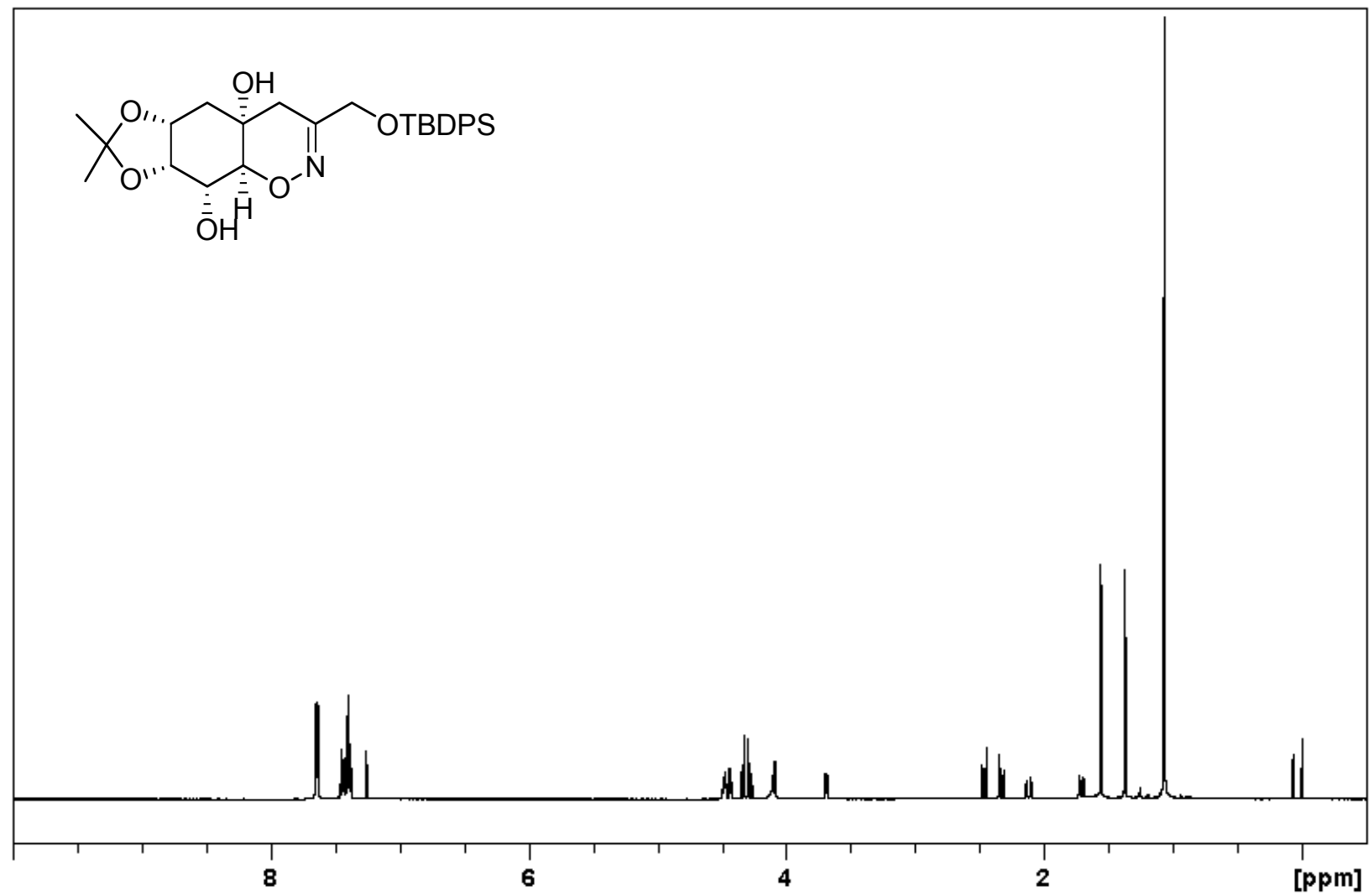

Figure 7: ${ }^{1} \mathrm{H}$ NMR spectrum of compound 21.

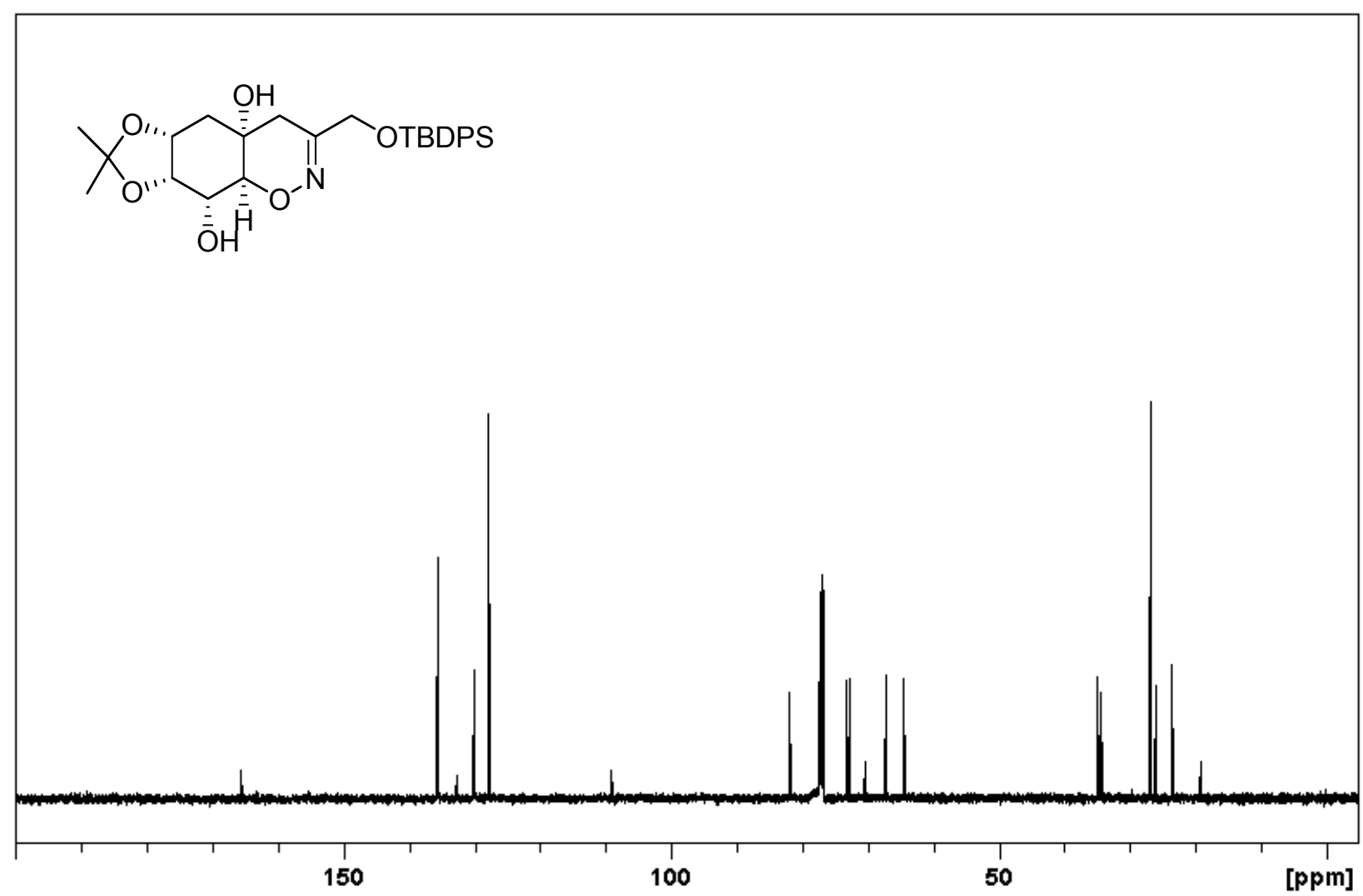

Figure 8: ${ }^{13} \mathrm{C}$ NMR spectrum of compound 21. 


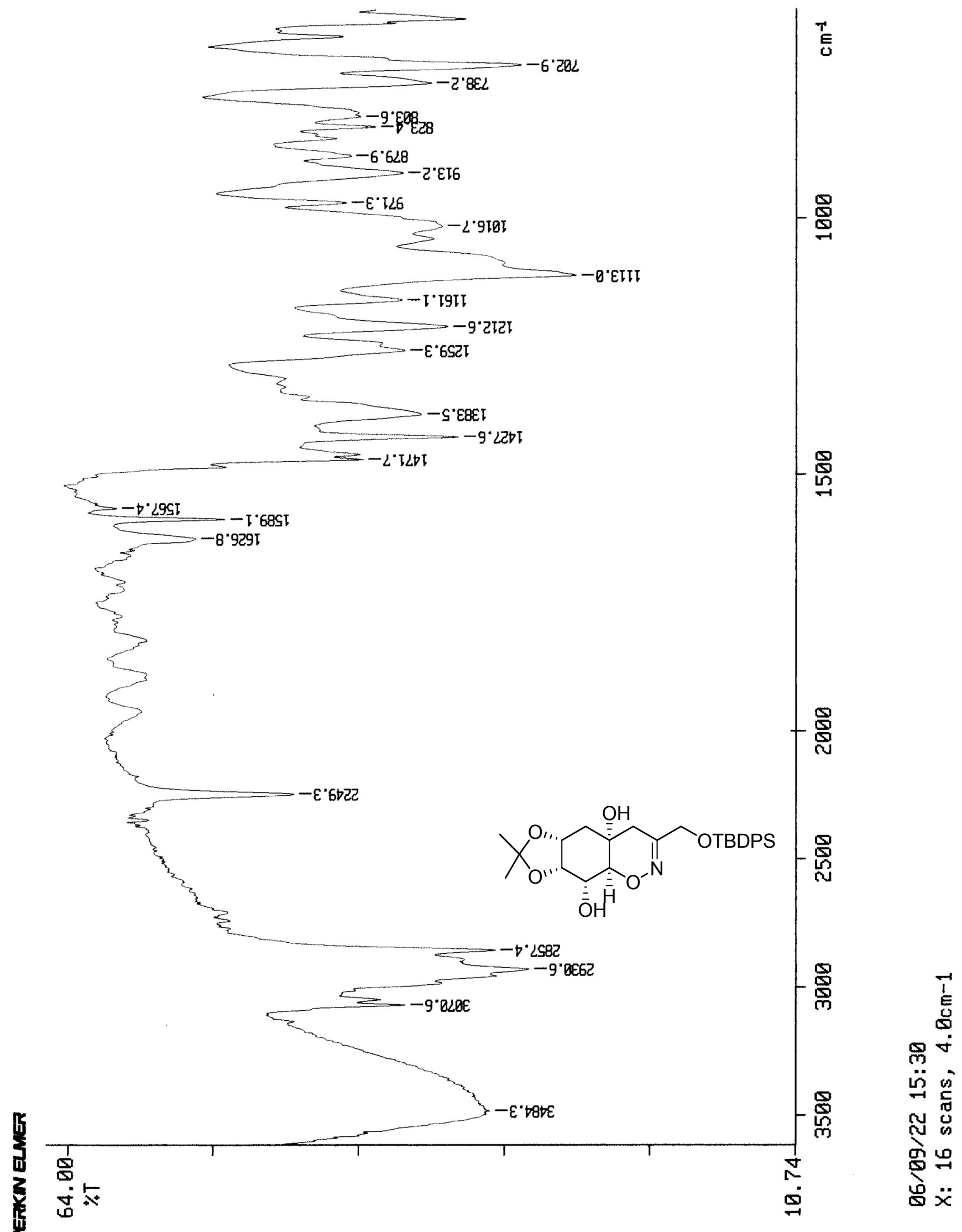

Figure 9: IR spectrum of compound 21 